\title{
Effect of Lactose on Acid Tolerance of Yogurt Culture Bacteria
}

\author{
Behannis Mena1, Kayanush Aryana ${ }^{2 *}$ \\ ${ }^{1}$ School of Agriculture and Food, Faculty of Veterinary and Agricultural Sciences, The University of Melbourne, \\ Melbourne, Australia \\ ${ }^{2}$ School of Nutrition and Food Sciences, Louisiana State University Agricultural Center, Baton Rouge, LA, USA \\ Email: ^karyana@agcenter.LSU.edu
}

How to cite this paper: Mena, B. and Aryana, K. (2020) Effect of Lactose on Acid Tolerance of Yogurt Culture Bacteria. Food and Nutrition Sciences, 11, 457-462. https://doi.org/10.4236/fns.2020.116033

Received: May 6, 2020

Accepted: June 9, 2020

Published: June 12, 2020

Copyright (C) 2020 by author(s) and Scientific Research Publishing Inc. This work is licensed under the Creative Commons Attribution International License (CC BY 4.0).

http://creativecommons.org/licenses/by/4.0/

\begin{abstract}
Lactose, the sugar naturally present in milk, provides energy to lactic acid bacteria used in fermented dairy foods. Increasing concentrations of lactose may improve survivability of lactic acid bacteria in the dairy foods and in human gut enhancing their probiotic benefits. Acid tolerance is an important probiotic characteristic. The objective was to determine the influence of lactose on acid tolerance of yogurt starter culture Streptococcus thermophilus ST-M5 and Lactobacillus bulgaricus LB-12. The M 17 broth was used for Streptococcus thermophilus ST-M5 and MRS broth was used for Lactobacillus bulgaricus LB-12. Lactose was added to both broths at $0 \%$ (control), $1 \%$, $3 \%$, and $5 \%(\mathrm{wt} / \mathrm{vol})$. Both broths were acidified to $\mathrm{pH} 2.0$. Upon sterilizing and tempering, both broths were inoculated. Acid tolerance was determined as viable counts in acidified broths after 120 minutes of incubations. In an incubation period of 2 hours, dilutions were plated every 30 minutes. Three replications were conducted. The highest acid tolerance for Streptococcus thermophilus ST-M5 and Lactobacillus bulgaricus LB-12, was observed in lactose concentration of $3 \%$ and $5 \%$ (wt/vol).
\end{abstract}

\section{Keywords}

Lactose, Acid Tolerance, Lactic Acid Bacteria

\section{Introduction}

Lactic acid bacteria (LAB) must survive the adverse conditions, such as an acidic environment of the stomach, prior to establishing in the lower gastrointestinal (GI) tract before conferring health benefits upon the human host. Tolerance to acid is an important probiotic trait, which determines LAB survival and growth [1] 
[2]. The LAB genera are typically made up of low proteolytic activity-fermentative strains, which means that they ingest and metabolize sugars to produce essentially lactic and acetic acids as their catabolic products.

The $\mathrm{pH}$ of the stomach, generally, ranges from 2.0 to 4.0 [3]. Berrada et al. [4] reported that it takes 90 minutes for the bacteria to be released after the time from entrance into the stomach. Therefore, strains selected to be used as probiotic bacteria should be able to tolerate acid for at least 90 minutes, attach to the epithelium, and grow in the lower intestinal tract before they can start providing health benefits [5]. Standards for acid tolerance of probiotic culture have been established as surviving $\mathrm{pH}$ of 2.0 for 2 hours [6].

Lactose is a disaccharide carbohydrate, composed of two monosaccharide components: D-glucose and $\mathrm{D}$-galactose [7]. This carbohydrate provides a ready source of energy to living organisms. Lactose is not metabolized directly by LAB. This carbohydrate is transferred into the bacterial cell where it is hydrolyzed to glucose and galactose by the lactose-permease enzymes [8]. The release of $\beta$-galactosidase from bacterial cells during the transit through the small intestine, appears to be linked to the mechanism of lactose digestion. Yogurt culture strains have the ability to hydrolyze lactose; thereby, yogurt cultures function as a source of enzymes in the intestinal tract [9].

Streptococcus thermophilus and Lactobacillus delbrueckii ssp. bulgaricus, are able to produce extracellular polysaccharides (EPS) that exert one of two functions: encapsulate the bacteria or are excreted into the extracellular environment [10]. This is considered as a natural encapsulation for the bacteria which protects them from adverse environmental conditions such as low $\mathrm{pH}$.

Authors wondered whether lactose would have a positive effect on acid tolerance of yogurt starter culture. To our knowledge, studies related to the effect of lactose on the acid tolerance of yogurt starter bacteria are scarce. The relationship that exists between several lactose concentrations and the bacterial survival is unknown. The aim of this study was to determine the influence of various concentrations of lactose on acid tolerance of yogurt starter culture Streptococcus thermophilus ST-M5 and Lactobacillus bulgaricus LB-12.

\section{Materials and Methods}

Acid tolerance was determined according to the method proposed by Pereira and Gibson [11], with slight modifications. Broths were acidified to $\mathrm{pH} 2$ using 1 N HCL and lactose was incorporated at $0 \%$ (control), 1\%, 3\%, and 5\% (wt/vol). Freshly thawed pure culture L. bulgaricus LB-12 and Streptococcus thermophiIus ST-M5 (Chr. Hansen, Milwaukee, WI) were inoculated separately with $1 \%$ (vol/vol) into control and lactose broths. For Lactobacillus bulgaricus LB-12, MRS broth (DifcoTM, Dickinson and company, Sparks, MD) was prepared and M17 broth (Oxoid, Basingstoke, UK) was prepared for Streptococcus thermophilus ST-M5. Inoculated broths were incubated anaerobically at $43^{\circ} \mathrm{C}$ for Lactobacillus bulgaricus LB-12 and aerobically at $37^{\circ} \mathrm{C}$ for Streptococcus thermophilus ST-M5 for 2 hours. Peptone water $(0.1 \% \mathrm{wt} / \mathrm{vol})$ was used to serially di- 
lute an aliquot of the inoculated broths which were subsequently pour plated in duplicate every 30 minutes up to 2 hours. Lactobacillus bulgaricus LB-12 was enumerated using Lactobacilli MRS agar [12] and M17 agar was used for enumeration of Streptococcus thermophilus ST-M5 [13]. Petri dishes were incubated anaerobically at $43^{\circ} \mathrm{C}$ for 72 hours for Lactobacillus bulgaricus LB-12 and aerobically at $37^{\circ} \mathrm{C}$ for 24 hours for Streptococcus thermophilus ST-M5. A colony counter (Darkfield Quebec Colony Counter, American Optical, Buffalo, NY) was used, after the incubation period, to assist the enumeration of colonies. Three replications were performed.

Bacterial counts were converted to $\log _{10}$ scale before analyzing the data with Proc Mixed SAS (version 9.3, SAS Institute Inc., Cary, NC). Significant differences between least square means were determined at $\alpha=0.05$ for main effects (lactose concentration and time) and interaction effects (lactose concentration $\times$ time) using Tukey adjustment.

\section{Results and Discussion}

The acid tolerance of Streptococcus thermophilus ST-M5 as influenced by lactose addition over incubation of 120 minutes is shown in Figure 1. A significant $(P<0.05)$ interaction effect for lactose concentration $\times$ time was noted. The main effects, namely lactose concentration and time (minutes), were also significant $(P<0.05)$. Treatments $3 \%$ and $5 \%(\mathrm{wt} / \mathrm{vol})$ lactose showed significantly higher viable cell counts compared to control and $1 \%$ (wt/vol) lactose at 0 and 120 minutes.

By subtracting $\log \mathrm{CFU} / \mathrm{mL}$ of 120 minutes from 0 minutes of incubation, mean log difference in the counts of Streptococcus thermophilus ST-M5 was obtained (Table 1). Lower bacterial death is indicated by a low number. The lowest

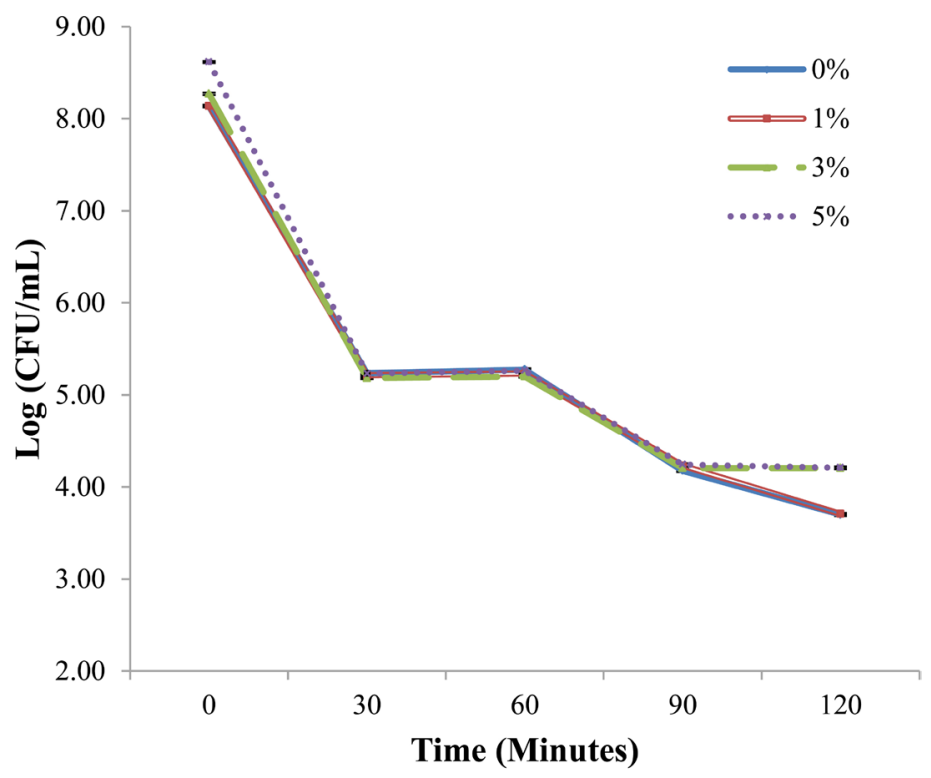

Figure 1. Influence of lactose concentration on acid tolerance of Streptococcus thermophilus ST-M5 over the incubation period of 120 minutes. 
bacterial death was observed for 3\% (wt/vol) lactose compared to the rest. According to Van de Guchte et al. [14], the LAB including Streptococcus thermophilus, grow generally between $\mathrm{pH} 5$ and 9. Streptococci ssp. are susceptible to low pH. Exposure of Streptococcus macedonicus to $\mathrm{pH} 3.5$ for 45 minutes resulted in almost 100\% death as reported by Papadimitriou et al. [15].

Acid tolerance of Lactobacillus bulgaricus LB-12 as influenced by lactose addition over incubation of 120 minutes is shown in Figure 2. Main effects, lactose concentration and time (minutes) were significant $(P<0.05)$. The interaction effect of lactose concentration $\times$ time was also significant $(P<0.05)$. Treatments $3 \%$ and $5 \%(\mathrm{wt} / \mathrm{vol})$ lactose had a significantly higher counts $(P<0.05)$ compared to control from 90 minutes of incubation. The $5 \%$ (wt/vol) lactose showed significantly the highest viable cell counts compared to control at 30, 90 and 120 minutes of incubation.

Mean log difference in the viable counts of Lactobacillus bulgaricus LB-12 (Table 1) was obtained as described above. The lowest bacterial death was observed for

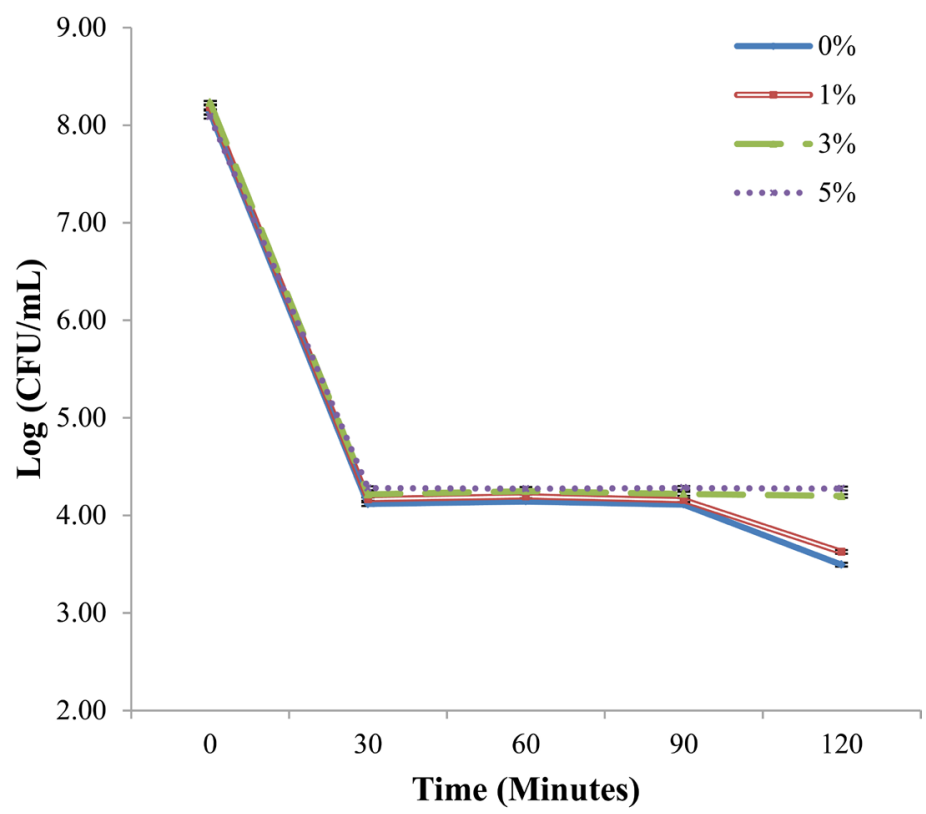

Figure 2. Influence of lactose concentration on acid tolerance of Lactobacillus bulgaricus LB-12 over the incubation period of 120 minutes.

Table 1. Influence of lactose concentrations in the presence of acid on mean log difference in the viable counts (Log CFU/mL) of Streptococcus thermophilus ST-M5 and Lactobacillus bulgaricus LB-12.

\begin{tabular}{ccc}
\hline $\begin{array}{c}\text { Added Lactose Concentration } \\
(\%)\end{array}$ & $\begin{array}{c}\text { Streptococcus thermophilus } \\
\text { ST-M5 }\end{array}$ & $\begin{array}{c}\text { Lactobacillus bulgaricus } \\
\text { LB-12 }\end{array}$ \\
\hline Control & 4.44 & 4.64 \\
One & 4.43 & 4.56 \\
Three & 4.06 & 4.04 \\
Five & 4.41 & 3.81 \\
\hline
\end{tabular}


$5 \%(\mathrm{wt} / \mathrm{vol})$ lactose compared to the rest. Lactobacillus bulgaricus is known to be more acid tolerant compared to Streptococcus thermophilus. Shah and Jelen [16] while studying the survival of lactic acid bacteria and their lactases under acidic conditions reported that both Lactobacillus delbrueckii ssp. bulgaricus and Streptococcus thermophilus survived $\mathrm{pH}$ as low as 1.5.

\section{Conclusion}

Higher lactose concentrations had a positive influence on acid tolerance of yogurt culture bacteria. This could also represent a potential way to improve the survivability of both these LAB and hence their probiotic benefits in the human gut.

\section{Acknowledgements}

This study was supported by USDA Hatch funds and Louisiana State University Agricultural Center.

\section{Conflicts of Interest}

The authors declare no conflicts of interest regarding the publication of this paper.

\section{References}

[1] Markowiak, P. and Śliżewska, K. (2017) Effects of Probiotics, Prebiotics, and Synbiotics on Human Health. Nutrients, 9, 1021. https://doi.org/10.3390/nu9091021

[2] Aryana, K.J. and Olson, D. (2017) A 100-Year Review: Yogurt and Other Cultured Dairy Products. Journal of Dairy Science, 100, 9987-10013. https://doi.org/10.3168/jds.2017-12981

[3] Papadimitriou, K., Alegría, Á., Bron, P.A., De Angelis, M., Gobbetti, M., Kleerebezem, M., Lemos, J.A., Linares, D.M., Ross, P., Stanton, C. and Turroni, F. (2016) Stress Physiology of Lactic Acid Bacteria. Microbiology and Molecular Biology Reviews, 80, 837-890. https://doi.org/10.1128/MMBR.00076-15

[4] Berrada, N., Lemeland, J.F., Laroch, G., Thouvenot, P. and Piaia, M. (1991) Bifidobacterium from Fermented Milks: Survival during Gastric Transit. Journal of Dairy Science, 74, 409-413. https://doi.org/10.3168/jds.S0022-0302(91)78183-6

[5] Pandey, K.R., Naik, S.R. and Vakil, B.V. (2015) Probiotics, Prebiotics and Synbiotics-A Review. Journal of Food Science and Technology, 52, 7577-7587. https://doi.org/10.1007/s13197-015-1921-1

[6] Gohran, M. (1994) Lactobacillus with the Ability of Colonization and Establishing in the Intestinal Tracts. Japan Patent 6-501624.

[7] Minard R. (1990) Introduction to Organic Laboratory Techniques: A Microscale Approach. Pavia, Lampman, Kriz \& Engel, Saunders. Penn State University.

[8] Neves, A.R., Pool, W.A., Kok, J., Kuipers, O.P. and Santos, H. (2005) Overview on Sugar Metabolism and Its Control in Lactococcus lactis-The Input from in Vivo NMR. FEMS Microbiology Reviews, 29, 531-554. https://doi.org/10.1016/j.femsre.2005.04.005

[9] Gilliland, S. E. and Kim, H.S. (1983) Influence of Yogurt Containing Live Starter 
Culture on Lactose Utilization in Humans. Animal Science Research Report. 113-116. http://afs.okstate.edu/research_reports/1983rr/83-22.pdf

[10] Boke, H., Aslim, B. and Alp, G. (2010) The Role of Resistance to Bile Salts and Acid Tolerance of Exopolysaccharides (EPSS) Produced by Yogurt Starter Bacteria. Archives of Biological Sciences, 62, 323-328. https://doi.org/10.2298/ABS1002323B

[11] Pereira, D.I. and Gibson, G.R. (2002) Cholesterol Assimilation by Lactic Acid Bacteria and Bifidobacteria Isolated from the Human Gut. Applied and Environmental Microbiology, 68, 4689-4693. https://doi.org/10.1128/AEM.68.9.4689-4693.2002

[12] Dave, R.I. and Shah, N.P. (1997) Viability of Yoghurt and Probiotic Bacteria in Yoghurts Made from Commercial Starter Cultures. International Dairy Journal, 7, 31-41. https://doi.org/10.1016/S0958-6946(96)00046-5

[13] Jordano, R., Serrano, E.C., Torres, M. and Salmeron, J. (1992) Comparison of Three M17 Media for the Enumeration of Streptococcus thermophilus in Fermented Dairy Products. Journal of Food Protection, 55, 999-1002. https://doi.org/10.4315/0362-028X-55.12.999

[14] Van de Guchte, M., Serror, P., Chervaux, C., Smokvina, T., Ehrlich, S.D. and Maguin, E. (2002) Stress Responses in Lactic Acid Bacteria. Antonie van Leeuwenhoek, 82, 187-216. https://doi.org/10.1023/A:1020631532202

[15] Papadimitriou, K., Pratsinis, H., Nebe-von-Caron, G., Kletsas, D. and Tsakalidou, E. (2007) Acid Tolerance of Streptococcus macedonicus as Assessed by Flow Cytometry and Single-Cell Sorting. Applied and Environmental Microbiology, 73, 465-476. https://doi.org/10.1128/AEM.01244-06

[16] Shah, N. and Jelen, P. (1990) Survival of Lactic Acid Bacteria and Their Lactases under Acidic Conditions. Journal of Food Science, 55, 506-509.

https://doi.org/10.1111/j.1365-2621.1990.tb06797.x 